\title{
A new species of parasitic copepod, Sarcotretes umitakae sp. n. (Siphonostomatoida, Pennellidae), on the rattail (Actinopterygii, Macrouridae) from the East China Sea, Japan
}

\author{
Daisuke Uyeno ${ }^{1, \dagger}$, Kaori Wakabayashi ${ }^{2, \ddagger}$, Kazuya Nagasawa ${ }^{3, \S}$ \\ I Faculty of Science, University of the Ryukyus, 1 Senbaru, Nishihara, Okinawa 903-0213, Japan 2 Fa- \\ culty of Marine Science, Tokyo University of Marine Science and Technology, 4-5-7 Konan, Minato, Tokyo \\ 108-8477, Japan 3 Graduate School of Biosphere Science, Hiroshima University, 1-4-4 Kagamiyama, Hi- \\ gashi-Hiroshima, Hiroshima 739-8528, Japan \\ † urn:lsid:zoobank.org:author:8BBFAA46-FD89-4CBB-A7FE-7E64933B162F \\ ¥urn:lsid:zoobank.org:author:4E66C125-69A6-4D03-8F17-6C9695E46429 \\ § urn:lsid:zoobank.org:author:25F4F960-4D1E-4EE2-B35A-902503FCA18E \\ Corresponding author: Daisuke Uyeno (daisuke.uyeno@gmail.com)
}

Academic editor: D. Defaye | Received 19 August 2012 | Accepted 14 November 2012 | Published 29 November 2012

urn:lsid:zoobank.org:pub:B758624F-BFA9-4E73-8E87-800A3E049335

Citation: Uyeno D, Wakabayashi K, Nagasawa K (2012) A new species of parasitic copepod, Sarcotretes umitakae sp. n. (Siphonostomatoida, Pennellidae), on the rattail (Actinopterygii, Macrouridae) from the East China Sea, Japan. ZooKeys 246: 1-10. doi: 10.3897/zookeys.246.3872

\begin{abstract}
A new species of copepod, Sarcotretes umitakae sp. n., of the siphonostomatoid family Pennellidae is described based on female specimens from the rattail Coelorinchus jordani Smith and Pope (Actinopterygii: Gadiformes: Macrouridae) caught in the East China Sea. This species is characterized by exhibiting the following characters: the large proboscis projects strongly; the head bears paired lateral processes which are bulbous and taper into a slender horn; the twisting neck is significantly longer than the trunk; and the trunk bears an anterior constriction with a reduced abdomen.
\end{abstract}

Copyright Daisuke Uyeno et al. This is an open access article distributed under the terms of the Creative Commons Attribution License 3.0 (CC-BY), which permits unrestricted use, distribution, and reproduction in any medium, provided the original author and source are credited. 


\section{Keywords}

Mesoparasitic copepods, Sarcotretes umitakae sp. n., new species, East China Sea, rattail, mesopelagic fishes

\section{Introduction}

Sarcotretes Jungersen, 1911, a pennellid genus, was originally established based on $S$. scopeli Jungersen, 1911 from Ireland, the eastern North Atlantic (Jungersen 1911). Wilson (1917) included six species in this genus: S. scopeli (type species), S. eristaliformis (Brian, 1908), S. gempyli (Horst, 1879), S. inflexus (Steenstrup and Lütken, 1861), S. nodicornis (Steenstrup and Lütken, 1861), and S. lobatus Wilson C.B., 1917. Subsequently, S. inflexus, S. nodicornis, S. gempyli, and S. lobatus were considered to be junior synonyms of $S$. scopeli by Hogans (1988). Recently, S. longirostris Ho, Nagasawa and Kim, 2007 was described, thus a total of three species are considered as valid in this genus at present (Ho et al. 2007). Members of the genus are parasitic on mesopelagic fishes (Cherel and Boxshall 2004), and they were often been found in food samples of penguins and whales (e.g. Cherel and Boxshall 2004; Ho et al. 2007). In this study, a new species of the genus is described based on females from the rattail Coelorinchus jordani Smith and Pope (Actinopterygii: Gadiformes: Macrouridae) caught in the mesopelagic zone of the East China Sea.

\section{Materials and methods}

Two specimens of the rattail $C$. jordani infected with copepods were caught in the East China Sea off the Tokara Islands, Kagoshima, Japan on 8 October 2011 during the cruise (UM-11-06) of the Umitaka-maru, a training and research vessel of Tokyo University of Marine Science and Technology (TUMSAT). The fishes were collected using an otter trawl towed for 30 minutes between two sites $\left(29^{\circ} 58.02^{\prime} \mathrm{N}\right.$, $127^{\circ} 43.79^{\prime} \mathrm{E}$ to $29^{\circ} 59.57^{\prime} \mathrm{N}, 127^{\circ} 44.28^{\prime} \mathrm{E}$ ) around $309 \mathrm{~m}$ in depth and, immediately after capture, they were preserved in $70 \%$ ethanol with copepods attached. In the laboratory, copepods were carefully removed from the tissues of fishes, and then soaked in lactophenol for a whole day before dissection. The appendages of the copepods were observed after dissecting with the method of Humes and Gooding (1964). Drawings were made with the aid of a drawing tube. Morphological terminology follows Huys and Boxshall (1991). Measurements (in millimeters) are shown as ranges, followed by means and standard deviations in parentheses. The flexed part was measured along the body axis. Type specimens are deposited in the crustacean collection at the National Museum of Nature and Science, Tsukuba (NSMT). The scientific name of fish follows Nakabo (2002). 


\section{Results}

\section{Order Siphonostomatoida Burmeister, 1835 \\ Family Pennellidae Burmeister, 1835 \\ Genus Sarcotretes Jungersen, 1911}

\section{Sarcotretes umitakae sp. $\mathrm{n}$.}

urn:Isid:zoobank.org:act:879FD1B6-AC17-4DD0-9E27-AFD4EF2A4DEF

http://species-id.net/wiki/Sarcotretes_umitakae

Figures $1-4$

Type material. Holotype female (NSMT-Cr 22253) and 2 paratypic females (NSMTCr 22254), ex Coelorinchus jordani Smith and Pope (Gadiformes: Macrouridae), taken off the Tokara Islands $\left(29^{\circ} 58.02^{\prime} \mathrm{N}, 127^{\circ} 43.79^{\prime} \mathrm{E}\right.$ to $\left.29^{\circ} 59.57^{\prime} \mathrm{N}, 127^{\circ} 44.28^{\prime} \mathrm{E}\right)$, Kagoshima, East China Sea, Japan, 308.5-309.3 m depth, 8 October 2011, reg. K. Wakabayashi and Y. Tanaka.

Type locality. off the Tokara Islands $\left(29^{\circ} 58.02^{\prime} \mathrm{N}, 127^{\circ} 43.79^{\prime} \mathrm{E}\right.$ to $29^{\circ} 59.57^{\prime} \mathrm{N}$, $127^{\circ} 44.28^{\prime}$ E), Kagoshima, East China Sea, Japan.

Description of postmetamorphic adult female. Body (Fig. 2A) elongate, comprising head, neck, and trunk. Total length 43.42 (from tip of cephalothorax to end of abdomen). Head (holdfast) composed of cephalosome to third pediger (Fig. 2A, $\mathrm{B})$, bearing elongate oral area projecting forward as cylindrical proboscis with multiple constrictions and mouth tube at its tip, with paired lateral processes (Fig. 2A, B) consisting of bulbous base drawn out into highly sclerotized horn-like process. Vestige of dorsal shield of cephalothorax and tergites of first to third visible on dorsal surface of head (Fig. 2D). Two paired small sclerites on ventral surface of basal region of oral cone (Fig. 2E). Neck (Fig. 2A) slender, longer than trunk, twisting and bearing bulge and constriction at posterior portion. Cylindrical trunk (Fig. 2A) 12.23 long (from enlarged end of neck to abdomen), 3.08 wide at widest part bearing paired hemispherical protrusions and reduced abdomen (Fig. 2F, G). Caudal rami absent.

Rostral area (Fig. 2H) triangular. Antennule (Fig. 3A) not segmented, located on sclerotized protrusion, bearing 10 blunt, long elements, and at least 17 short elements; 1 long distal seta with bifurcated tip. Antenna (Fig. 3B) subchelate, 3-segmented; proximal segment, unarmed; middle segment stout with a pointed process on innerdistal corner, hollowed out to receive terminal claw; terminal segment representing terminal claw with single basal seta. Mandible (Fig. 3C) located on lateral side of base of oral cone (Fig. 2E), represented by sclerotized process with unequal processes tip. Maxillule (Fig. 3D) bilobate; large inner lobe tipped with two naked setae; small outer lobe bearing one naked seta. Maxilla (Fig. 3E) 2-segmented; proximal segment rod-like, bearing round protrusion with pointed process in middle portion; terminal segment rod-like, tipped with curved spinulose process, small pointed process, and setulous lobe (Fig. 3F). Maxilliped absent. 

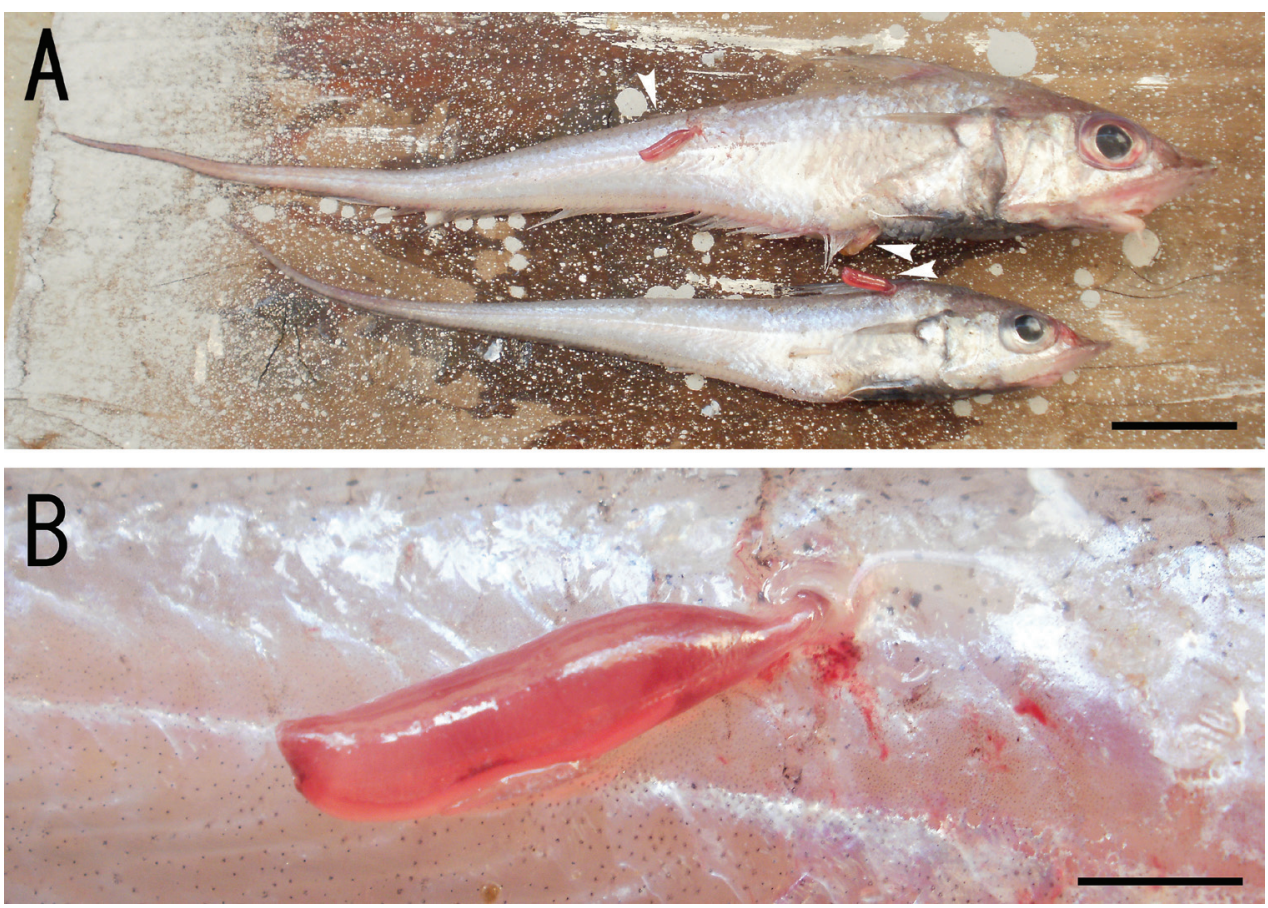

Figure I. Sarcotretes umitakae sp. n., female on Coelorinchus jordani Smith and Pope. A two specimens of $C$. jordani (181.5 mm TL and $142.8 \mathrm{~mm} \mathrm{TL}$ ) carrying the type series of Sarcotretes sp. n. (arrowheads) B coloration in life of paratype NSMT-Cr 22254 attached to host's body. Scale bars: A=20 mm; B=3 mm.

Legs 1 to 4 occurring tightly together and located between paired lateral processes of holdfast. Legs 1 and 2 (Figs. 3G, 4A) biramous, composed of inter coxal sclerites, protopods, and 2-segmented rami. Leg 3 (Fig. 4B) uniramous, without endopod; leg armature formula as follows:

\begin{tabular}{c|c|c|c}
\hline & Protopod & Exopod & Endopod \\
\hline Leg 1 & $1-0$ & I- 1 I I, I, 5 & $0-1 ; 7$ \\
\hline Leg 2 & $1-0$ & I-1; I, I, 5 & $0-1 ; 7$ \\
\hline Leg 3 & $1-0$ & $0-0 ;$ I, I, 4 & absent \\
\hline
\end{tabular}

Leg 4 (Fig. 4C) represented by vestigial intercoxal sclerite. Legs 5 and 6 absent.

Variability of female. The necks of all paratypes twist and turn in complex fashion (Fig. 4D). Measurements of the body parts of the specimens from the type series $(\mathrm{n}=$ 3 ) are as follows: body length (anterior margin of the head to distal end of the posterior processes on the trunk) 30.26-50.12 (41.27 \pm 10.10$)$; trunk length 11.27-13.48 $(12.33 \pm 1.11)$; trunk width $2.84-3.17(3.03 \pm 0.17)$.

Male. Unknown.

Site. The copepod attaches to various parts of the body surface of the host fishes (Fig. 1A). The head to the neck of the copepod was embedded in the host's musculature, and the trunk was protruded into the water (Fig. 1B) 


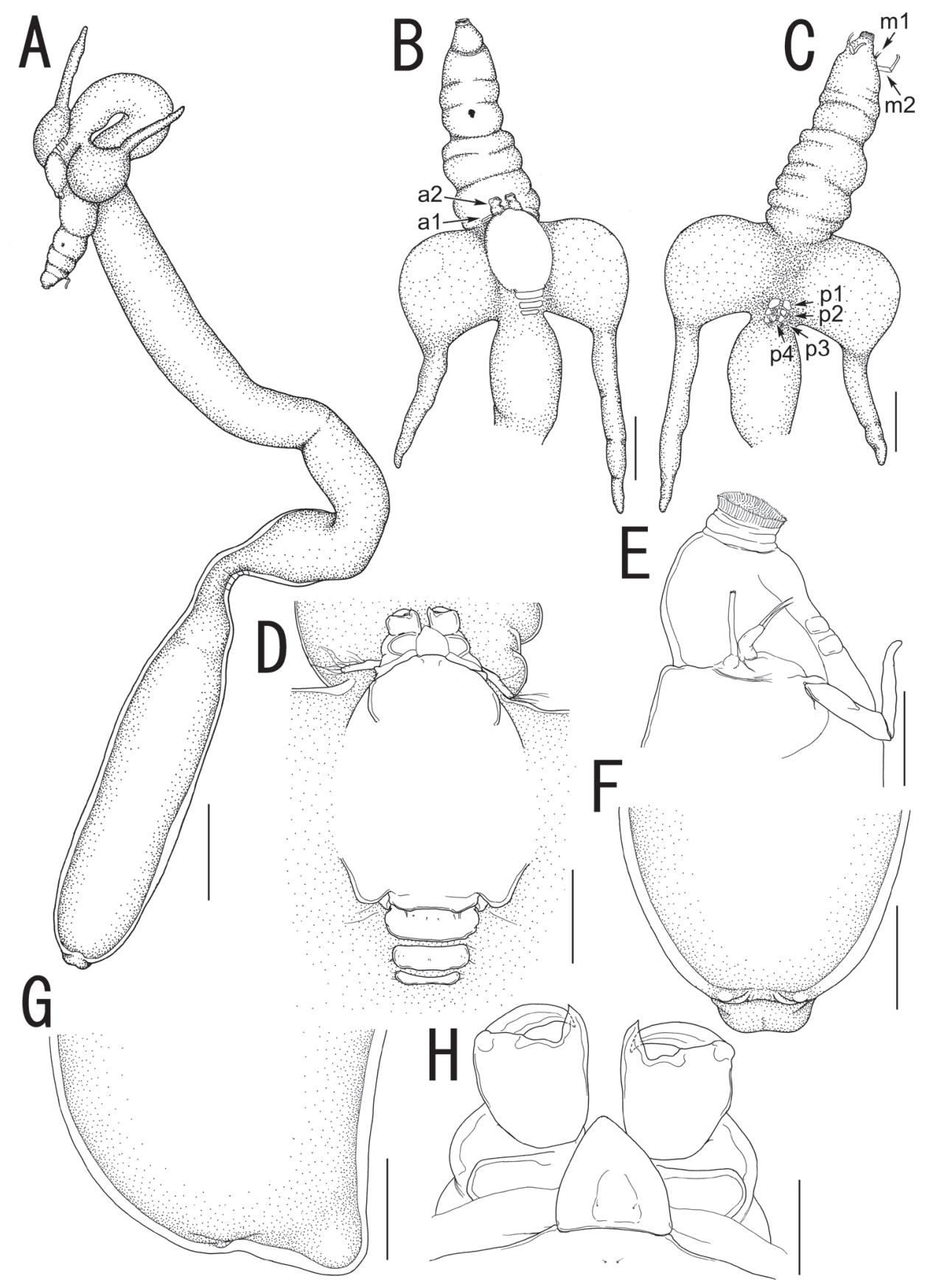

Figure 2. Sarcotretes umitakae sp. n., female, holotype NSMT-Cr 22253. A habitus B anterior portion of body, dorsal, a1 = antennule, a 2 = antenna $\mathbf{C}$ same, ventral, $\mathrm{m} 1=$ maxillule, $\mathrm{m} 2=$ maxilla, $\mathrm{p} 1=\operatorname{leg} 1$, p2 $=\operatorname{leg} 2, \mathrm{p} 3=\operatorname{leg} 3, \mathrm{p} 4=$ vestige of leg $4 \mathbf{D}$ vestige of dorsal cephalothoracic shield $\mathbf{E}$ tip of proboscis, lateral $\mathbf{F}$ posterior portion of body, ventral $\mathbf{G}$ same, lateral $\mathbf{H}$ rostral area and antennae, dorsal. Scale bars: $\mathbf{A}=3 \mathrm{~mm} ; \mathbf{B}, \mathbf{C}, \mathbf{F}, \mathbf{G}=1 \mathrm{~mm} ; \mathbf{D}=500 \mu \mathrm{m} ; \mathbf{E}=300 \mu \mathrm{m} ; \mathbf{H}=150 \mu \mathrm{m}$. 


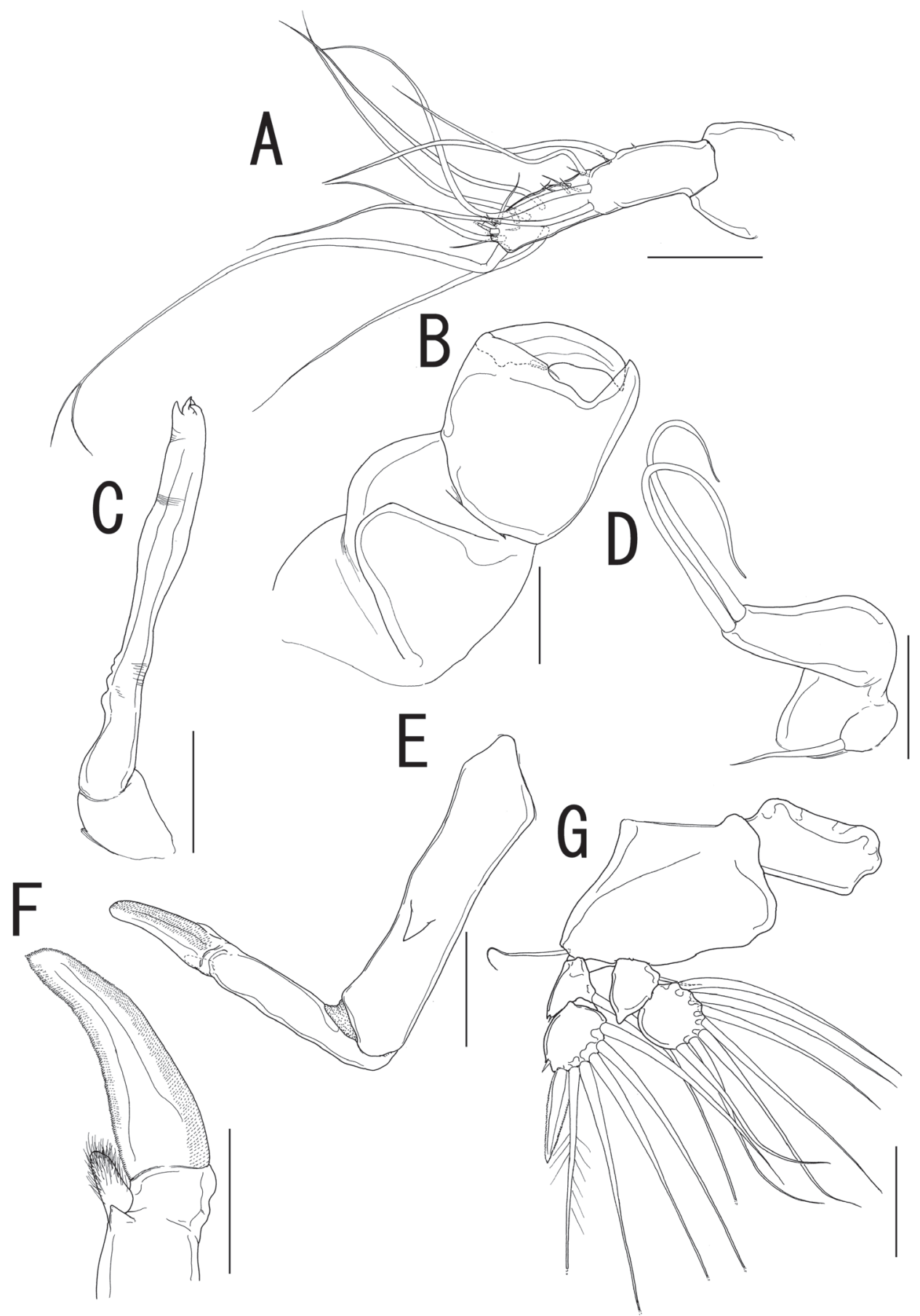

Figure 3. Sarcotretes umitakae sp. n., female, holotype NSMT-Cr 22253. A left antennule, anterior B left antenna, anterior $\mathbf{C}$ left mandible $\mathbf{D}$ left maxillule $\mathbf{E}$ left maxilla, lateral $\mathbf{F}$ distal part of left maxilla $\mathbf{G}$ right leg 1, anterior. Scale bars: A, B, E, G=100 $\mu \mathrm{m} ; \mathbf{C}, \mathbf{D}=70 \mu \mathrm{m} ; \mathbf{F}=50 \mu \mathrm{m}$. 


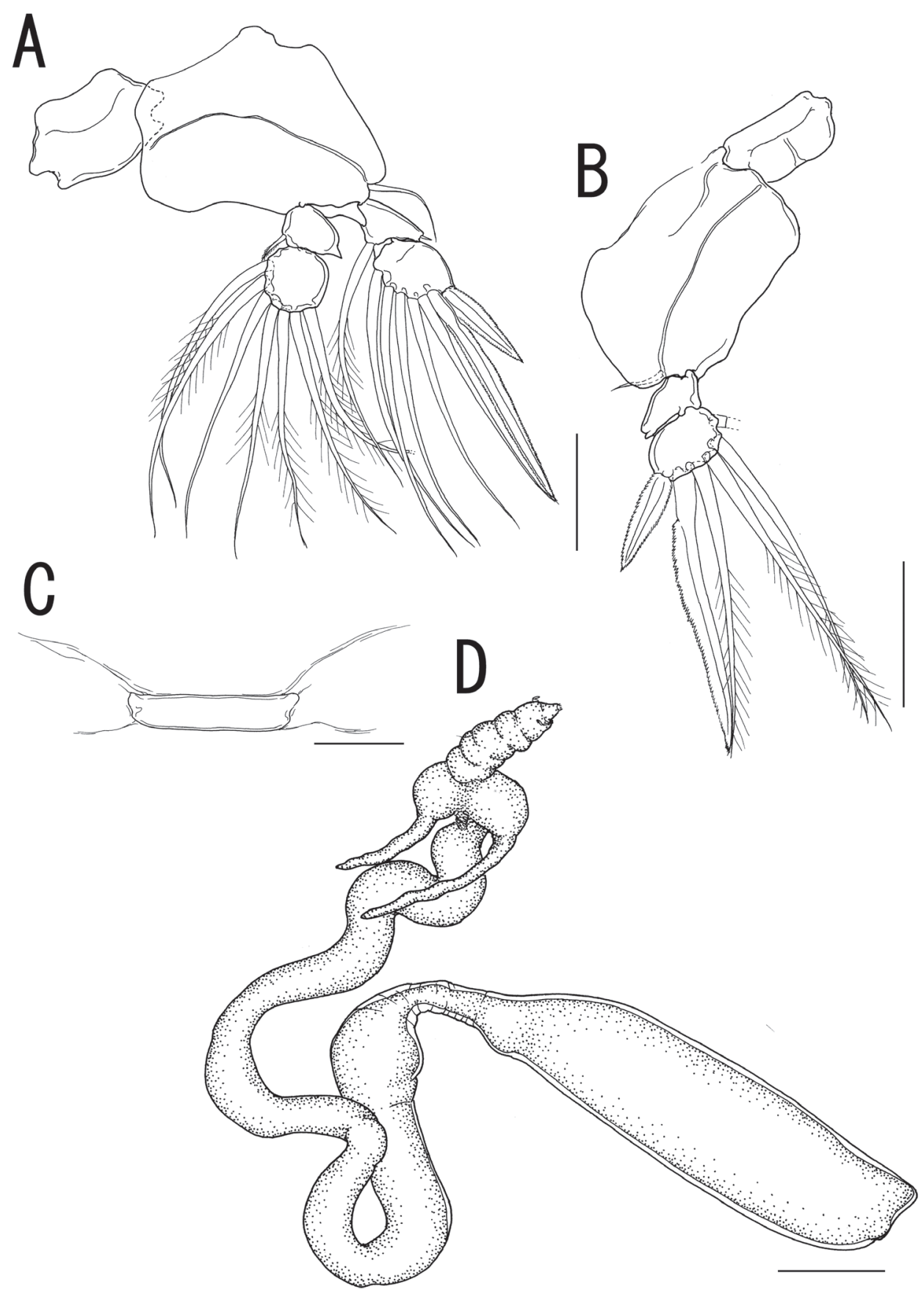

Figure 4. Sarcotretes umitakae sp. n., female, holotype NSMT-Cr 22253. A left leg 2, anterior B right leg 3, anterior $\mathbf{C}$ vestige of leg 4. Sarcotretes umitakae sp. n., female, paratype NSMT-Cr 22254 D habitus. Scale bars: A, B=100 $\mu \mathrm{m} ; \mathbf{C}=30 \mu \mathrm{m} ; \mathbf{D}=3 \mathrm{~mm}$. 
Etymology. The specific name "umitakae" refers to the Umitaka-maru, a training and research vessel of TUMSAT.

Remarks. Currently, three species of Sacotretes: S. eristaliformis, S. longirostris, and S. scopeli, are considered to be valid (Ho et al. 2007). Sarcotretes umitakae sp. n. differs from S. eristaliformis and S. scopoli by having the holdfast with paired bulbous swellings drawn out into an elongate, horn-like process (vs. bulbous with or without a blunt tip) and the neck approximately 3 times as long as the trunk (vs. nearly as long as the trunk in S. eristaliformis and less than 3/4 of the trunk length in S. scopeli) (Brian 1912; Hogans 1988; Boxshall 1989; Cherel and Boxshall 2004; Ho et al. 2007). The two specimens described as S. eristaliformis by Kabata and Gusev (1966) were judged to be S. scopeli on the basis of a body length of 15.8-21.2 mm, the neck being shorter than the trunk, and relative length of the proboscis (Hogans 1988; Ho et al. 2007). In addition, S. scopeli differs from the new species by the absence of the vestige of leg 4 (vs. presence) (Boxshall 1989; Cherel and Boxshall 2004). Sarcotretes longirostris has the neck longer than the trunk like $S$. umitakae sp. n. and only these 2 species possess an extremely long proboscis among their congeners. Sarcotretes longirostris is, however, easily distinguishable from the new species by having the following characters: slender lateral head processes without swollen basal portions (vs. a bulbous swelling with a slender process); a not defined rostral area (vs. triangular); and a large and conical reduced abdomen, protruding to posterior (vs. small and non-conical and slightly protruded to posterodorsal) (Ho et al. 2007). In addition, the trunk has an anterior constriction in S. umitakae sp. n. not shared with any of the three known species (Figs. 2A, 4D).

\section{Discussion}

Despite the fact that some morphological characters of Sarcotretes species (e.g. the shape of the holdfast, the length and flexure of the neck, and the length of the proboscis) show variability, they have been conventionally used to distinguish the species in this genus (Hogans 1988). Because these characters vary according to the site of attachment to the host and the age of the parasite, species identification using such characters may not make sense. Actually, based on those characters, Wilson (1917) had recognized 6 species as valid, but later, 4 species (S. gempyli, S. inflexus, S. lobatus, and S. nodicornis) were regarded as junior synonyms of S. scopeli by Hogans (1988). Nonetheless, we consider that such characters as the length of the proboscis and the shape of the lateral horns on the head, which were used in the key given by Wilson (1917), are useful identification characters. These characters do exhibit variability but there is no overlap between in S. umitakae sp. n. and existing species. Sarcotretes umitakae sp. n. and S. longirostris possess a strongly projecting proboscis which is not shared with other congeners. The lateral process of $S$. umitakae sp. n. comprising a bulge with a pointed tip is similar to that of $S$. scopeli and S. eristaliformis, but the greatly elongated tip in $S$. umitakae sp. n. is apparently distinguishable (see Brian 1912, pls. 9, 10; Hogans 1988, fig. 2b; Boxshall 1989, fig. 3; present study, Fig. 2). 
Although a great care is required, it is considered that these characters can provide reliable evidence of species identity. On the other hand, all three specimens of $S$. umitakae sp. $\mathrm{n}$. have a neck with a posterior protrusion and a constriction behind it. However, this character cannot be used to identify $S$. umitakae sp. n. because a similar character was observed in some specimens of S. eristaliformis and S. scopeli (see Brian 1912; Boxshall 1989).

The discovery of $S$. umitakae sp. $\mathrm{n}$. in this study shows that there are at least 2 species of the genus in Japanese waters.

\section{Key to females of the species of Sarcotretes}

1 Proboscis slightly projecting; holdfast composed of broad base with or without terminal process; neck shorter than or as long as trunk .................. 2

- $\quad$ Proboscis elongate, strongly projecting; holdfast comprising slender processes; neck significantly longer than trunk............................................................. 3

2 Body up to approximately $25 \mathrm{~mm}$ long; neck shorter than trunk; leg 4 absent ..................................................................................... S. scopeli

- $\quad$ Body approximately $45 \mathrm{~mm}$ or longer (about twice length of $S$. scopeli); neck about as long as trunk; vestige of leg 4 (intercoxal sclerite) present.

S. eristaliformis

3 Slender, horn-like lateral processes on head (holdfast); trunk not constricted; reduced abdomen conical, projecting posteriorly ....................S. longirostris

- Lateral process bulbous tapering into slender, elongate horn; trunk with anterior constriction; abdomen reduced, vestigial ............S. umitakae sp. $\mathbf{n}$.

\section{Acknowledgements}

We would like to acknowledge the captain and crew of the Umitaka-maru (TUMSAT) for their support during the cruise. We also thank Dr. Tadashi Tokai (TUMSAT), an organizer of the cruise, for his courtesy and understanding of our study on the parasitic copepod fauna of the East China Sea. We are grateful to Dr. Yuji Tanaka (TUMSAT) for his assistance in collecting the specimens onboard the vessel. Part of this work received a financial support from Grants-in-Aid for JSPS Fellows (No. 23-4311 to D.U.).

\section{References}

Boxshall GA (1989) Parasitic copepods of fishes: a new genus of the Hatschekiidae from New Caledonia, and new records of the Pennellidae, Sphyriidae and Lernanthropidae from the South Atlantic and South Pacific. Systematic Parasitology 13: 201-222. doi: 10.1007/ BF00009746 
Brian A (1912) Copépodes parasites des poissons et des échinides provenant des campagnes scientifiques de S.A.S. le Prince Albert Ier de Monaco (1866-1910). Résultats des Campagnes Scientifiques du Prince Albert Ier de Monaco 38: 1-58.

Cherel Y, Boxshall GA (2004) Sarcotretes (Copepoda: Pennellidae) parasitizing myctophid fishes in the Southern Ocean: new information from seabird diet. Journal of Parasitology 90: 1288-1292. doi: 10.1645/GE-3384

Ho J-S, Nagasawa K, Kim I-H (2007) Sarcotretes longirostris sp. n. (Copepoda, Pennellidae) parasitic on bluefin driftfish (Psenes pellucidus) found in the stomach of the short-finned pilot whale caught off Japan. Journal of Crustacean Biology 27: 116-120. doi: 10.1651/S-2751.1 Hogans WE (1988) Review of Sarcotretes Jungersen, 1911 (Copepoda: Pennellidae) from midwater and demersal fishes in the north Atlantic Ocean. Canadian Journal of Zoology 66: 1371-1375. doi: 10.1139/z88-201

Humes AG, Gooding RU (1964) A method for studying the external anatomy of copepods. Crustaceana 6: 238-240. doi: 10.1163/156854064X00650

Huys R, Boxshall GA (1991) Copepod evolution. The Ray Society, London, 468pp.

Jungersen HFE (1911) On a new gymnoblastic hydroid (Ichthyocodium sarcotretis) epizoic on a new parasitic copepod (Sarcotretes scopeli) infesting Scopelus glacialis Rhdt. Videnskabelige Meddelelser fra Dansk Naturhistoriske Forening, Copenhagen 64: 1-34.

Kabata Z, Gusev AV (1966) Parasitic Copepoda of fishes from the collection of the Zoological Institute in Leningrad. Journal of the Linnean Society, Zoology 46: 155-207.

Nakabo T (2002) Macrouridae. In: Nakabo T (Ed) Fishes of Japan with Pictorial Keys to the Species, English Edition. Tokai University Press, Tokyo, 417-435.

Wilson CB (1917) North American parasitic copepods belonging to the Lernaeidae with a revision of the entire family. Proceedings of the United States National Museum 53: 1-150. doi: 10.5479/si.00963801.53-2194.1 